\title{
Addendum: Multiscale metallic metamaterials
}

Xiaoyu Zheng, William Smith, Julie Jackson, Bryan Moran, Huachen Cui, Da Chen, Jianchao Ye, Nicholas Fang, Nicholas Rodriguez, Todd Weisgraber and Christopher M. Spadaccini

Nature Materials 15, 1100-1106 (2016); published online 18 July 2016; corrected after print 7 March 2017.

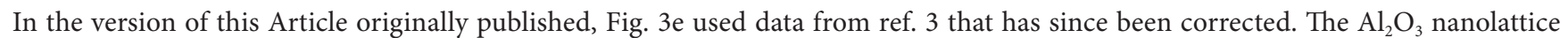
dataset has been corrected to reflect this. In addition, the $\mathrm{Al}_{2} \mathrm{O}_{3}$ hollowtube dataset from ref. 14 has been added to the plot. These changes do not affect the data or findings of the present study. The new figure is shown below.

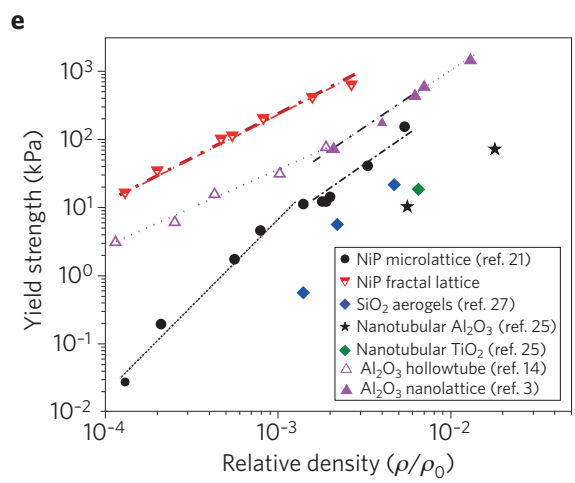

